\title{
How to Unite Scientific Reasoning and Practical Knowledge in Teacher Education As Illustrated by a Postgraduate Course
}

\author{
Stefan Sellbjer ${ }^{1, *} \&$ Håkan Jenner ${ }^{1}$ \\ ${ }^{1}$ School of Education, Psychology and Sport Science, Linnaeus University, 35195 Växjö, \\ Sweden \\ *Corresponding author: School of Education, Psychology and Sport Science, Linnaeus \\ University, 35195 Växjö, Sweden
}

Tel: 46-470-708-866_E-mail: Stefan.Sellbjer@lnu.se

Received: October 3, 2012 Accepted: December 6, 2012 Published: December 16, 2012

doi:10.5296/ije.v4i4.2492 URL: http://dx.doi.org/10.5296/ije.v4i4.2492

\begin{abstract}
In this article the question of how to unite scientific reasoning and practical knowledge is brought to the fore Experiences from a postgraduate course in special education are discussed, since attempts to make different vocational education programs more academic often lead to special problems. The overarching question connected with scientific reasoning can be formulated thus: "How do we gain assured knowledge about reality?", a question with its roots in ontological, epistemological and methodological issues. Using such questions as a starting point for reflection proved to be a way to practice scientific thinking. In order to deepen the understanding of how knowledge is constructed, as well as of the contents of practical knowledge, tacit knowledge and scientific reasoning, some distinctions are made. First, three forms of knowledge products and knowledge processes are distinguished and secondly, the issue of unconscious and automatized knowledge is elaborated on.
\end{abstract}

Keywords: scientific knowledge; practical knowledge; reflection; process; product 


\section{Introduction}

One of the objectives of higher education is to develop students' ability to conduct scientific reasoning on the basis of the philosophy and the theory of science. This objective is uncontroversial in itself. However, attempts to make different vocational education programs more academic lead to special problems (teachers, social workers, nurses, and police officers being examples of such target groups.) Then the question of how to unite scientific reasoning and practical knowledge is brought to the foreground. In order to deepen the understanding of how the educator can be successful in this respect, the concepts must be subjected to specific considerations and theoretical elaboration.

Against this background a postgraduate course in special education will be discussed. The course is being taught at Linnaeus University, Sweden, and is geared towards in-service teachers with at least three years' teaching experience. It is run on a part-time basis ( $50 \%$ of a full-time academic load) over three years, and leads to a second-cycle degree in special education. The students' professional background ranges from preschool and elementary school to high school.

This article presents experiences from the course, focusing on the efforts to get the students to see a connection between their practical knowledge, on the one hand, and scientific reasoning, on the other. In the next section the theoretical framework is elaborated on. Finally, the course is reviewed in connection with this framework, and some implications for teacher education are presented.

\section{The course in special education}

'Tacit knowledge', 'reflection,' and 'reflective practitioner' are some of the central concepts underlying the course. In line with Michael Polanyi's (1967) reasoning, tacit knowledge is viewed as implicit theses that can be brought to light when needed. (That is, tacit knowledge is not regarded as impossible to verbalize as in the Wittgensteinian sense, which is an important distinction.) Practical knowledge cannot always be explained in detail, but if this type of knowledge is considered fundamentally impossible to describe, it also becomes impossible to expose its foundations to critical testing. Donald Schön's work (1983, 1987) is of course important in this context, as is his concept of 'the reflective practitioner.' A reflective practitioner is someone who is "a researcher in practice," who reflects on the phenomena he or she encounters in practice, and questions earlier interpretations that have been implicitly underlying his or her actions.

Scientific reasoning can be a medium for the development of a reflective attitude towards one's practice. The idea is to influence the practitioner's way of thinking. It should, then, also be vital to bring scientific ideas down to earth from abstract theory and ground them in the students' praxis. These ideas can then be made a tangible part of their professional actions and professional roles (i.e., values and professional ethics). 


\subsection{Scientific reasoning in practice}

The overarching question connected with scientific reasoning can be formulated thus: How do we gain assured knowledge about reality? This question has its roots in the ontological question "What is reality?", the epistemological question "What is assured knowledge?”, and the methodological question "How do we gain assured knowledge?” In the course in special education these questions were transferred to a practical level, and questions such as the following were put forward: Is "normalcy" something "absolute" that is possible to measure, or is it something we determine in some other way? Can I claim to know about something I have never experienced first hand (for example, what it is like to be seen as deviant)? Does having a lot of information automatically enable me to better understand another person? How are my views of other people and the environment influenced by my preconceptions and prejudices? Who decides what "the truth" is when there is a lack of consensus (e.g., between the teacher and pupil or parents), and how does this interpretive priority come about?

Using these questions as a starting point for reflection proved to be a way to practice scientific thinking. During one class session scientific issues were discussed in this manner. Here are some examples: The question "Can I claim to know about something I have never experienced first hand?" caused some perplexity, but could be analyzed with the help of Bertrand Russell's concepts of 'knowledge by acquaintance' and 'knowledge by description.' The question "Does having a lot of information automatically enable me to better understand another person?" was discussed, with supporting evidence from various works of investigation and from remedial measures. It was agreed that the answer is "no," and that the critical factor is the theoretical orientation (or other starting points) we use as a basis for compiling information. Different points of departure can yield different answers.

This part of the course was rounded off with a presentation of the basics of positivism and hermeneutics. Ways of acquiring knowledge, types of information, the objectives of knowledge, scientific criteria, and the attitude of the researcher were specifically addressed.

The next step was to begin to consider how professional knowledge is constructed.

\subsection{Reflection on professional knowledge}

Professional knowledge can be described in terms of diplomas and certificates, positions and years of service. More difficult to pin down, but no less important, is the ability to perform adequately in different situations. Professional knowledge can also be described in terms of the attitudes and values that guide behavior. But these fundamental values whatever they may be - are not a matter of chance. They are based on the fruits of study, experiences, and personal encounters.

One part of the course was to consider the content of professional knowledge. The idea was to stimulate reflection on how one constructs professional knowledge from one's own school memories, from encounters with pupils and parents, discussions with colleagues, and other sources. The students were instructed to write about a specific event or discussion that had brought about a "change of perspective," i.e. something that had changed their thinking 
or made them to view their professional practice differently.

The students completed the assignment in the form of short narratives. Some wrote about teachers from their school days - teachers that had become good role models or bad examples. Some of the narratives contain candid descriptions of how you can learn from your mistakes, or from having your blind spots pointed out to you. Colleagues who have functioned as formal or informal mentors are named in some of the narratives, and experience with other types of further education is referred to. Many of the students describe their own experiences of being bullied, what their friends have said about school, their own children's school experiences, and other non-professional sources of knowledge that have influenced their views on the practice of teaching.

To sum up, it appears that the students have vivid memories of meaningful events. Even before the writing assignment they were aware that people carry these memories with them in their professional practice. The point here was to bring the memories to life and to raise the students' awareness of how knowledge is constructed.

\subsection{Reflection on school experiences}

Another element of the course was a writing assignment in which the students were to write about a pupil from their own school days: a pupil who was seen as deviant. In short, the assignment was to describe the pupil in writing and then read and discuss the texts in groups. Finally, the students were to revise their texts on the basis of group discussions.

The results were discussed in class. It was observed that the initial spontaneous versions of the texts were often direct and relatively free from assumptions about, for instance, causality. The revised texts often contained explanations and reflections from a professional perspective. This provides us with an example of how we construct knowledge, for instance through dialogue with others. But if one wants to describe the basic essence found in the material, it must be processed in some way.

Using qualitative methods, one of the authors analyzed the written material. The most conspicuous themes in the analysis were presented to the students, for example, social rules in the classroom (e.g. the rule not to associate with deviants for fear of being labeled a deviant oneself, a sort of "guilt by association"), cultural differences, and teacher reactions (e.g. the lack of support from the teacher or outright negative teacher behavior, such as making fun of the deviant pupil). The study's validity was presented as a question of whether or not its conclusions could be seen as plausible as judged by the informed observer. As a secondary metacognitive element it was emphasized that what we had agreed on was not true knowledge, but that the exercise was a demonstration of how knowledge is constructed and validated.

\section{Further theoretical considerations}

It seems fruitful to make some distinctions in order to deepen the understanding of how knowledge is constructed as well as the contents of practical knowledge, tacit knowledge and 
scientific reasoning. First, we will distinguish three forms of knowledge products and knowledge processes, and insert them in a model. Secondly, we will discuss the issue of unconscious and automatized knowledge.

The reasoning is based on the premise that there are distinctive differences between knowledge process and knowledge product, while at the same time these elements interchange.

Knowledge process is how you learn and the product what you learn. Knowledge processes take part all time and are interwoven with knowledge products. You learn something (process), and the moment you have learned whatever it is, you possess another knowledge product. Knowledge processes are tacit (you do not observe how you learn something), but knowledge products are more explicit (most of the time you are able to formulate what you have learned). Knowledge products are not stable, and in practice knowledge processes and knowledge products interchange.

\subsection{Three forms of knowledge}

This section focuses on three forms of knowledge products and knowledge processes and the question why knowledge processes are tacit and whether this applies to all forms of knowledge processes.

In the pedagogic domain we usually distinguish between two forms of knowledge, that is everyday knowledge and scientific knowledge or scientific reasoning. Everyday knowledge springs from everyday human life and is also what is most useful in this context. It consists of things we take for granted without having examined it more systematically. Via reflection or distancing, for instance, steps are taken from what is intuitive and taken for granted to something more thoroughly thought out, that is knowledge based on scientific reasoning.

Bruner (1996) refers in this regard to folk theories, Vygotsky (1934/1962) makes a distinction between spontaneous and scientific concepts, Dewey (1910/1991) separates empirical and reflective thinking, and Piaget in his development theory (Flavell, 1977) indicates an increase in rational and logical thinking.

In Table 1, level two and three represents the distinction between everyday knowledge and knowledge based on scientific reasoning. I return to level one in the next section. Knowledge formation is in level two an three supposed to be explicit, in that knowledge processes take place intentionally and can be made conscious at any time. The difference between the two levels is that learning at level two is experiential, while at level three it is supposed to be reflective, a distinction we will recur to later. The knowledge process is in both cases assumed to be discontinuous, since we do occasionally, or even habitually, let go of our conscious intention. At level two the knowledge product is termed everyday knowledge and everyday folk theory, while at level three it is called scientific knowledge, scientific theory or knowledge based on scientific reasoning. (Alternatively it can be called reflective knowledge and reflective theory. These terms have, however, been avoided so as not to risk confusing them with the knowledge process at level three.) 
Table 1: Knowledge process and knowledge product in relation to three levels of learning. Level one is further elaborated in the next section

\begin{tabular}{lll}
\hline Level & $\begin{array}{l}\text { Knowledge process + learning } \\
\text { (thinking) }\end{array}$ & Knowledge product \\
\hline 1 & $\begin{array}{l}\text { unconscious - automatized learning } \\
\text { (cf. Kihlstrom's automatic “thought } \\
\text { process") }\end{array}$ & $\begin{array}{l}\text { intuitive knowledge/intuitive theories (cf. } \\
\text { next section) }\end{array}$ \\
\hline $\begin{array}{l}\text { conscious- experiential learning/ } \\
\text { experiential dialogue } \\
\text { (cf. Dewey's empirical thinking) }\end{array}$ & $\begin{array}{l}\text { everyday knowledge/everyday theories } \\
\text { (cf. Bruner's folk theories) }\end{array}$ \\
& $\begin{array}{l}\text { conscious- reflective learning/ } \\
\text { reflective dialogue } \\
\text { (cf. Dewey's reflective thinking) }\end{array}$ & $\begin{array}{l}\text { scientific knowledge/scientific } \\
\text { theory/knowledge based on scientific } \\
\text { reasoning } \\
\text { (cf. Vygotsky’s scientific concepts) }\end{array}$ \\
\hline
\end{tabular}

The distinction between experiential and reflective learning may be illustrated from Dewey (1910/1991), who maintains that what he calls empirical thinking is based on habits that do not provide any understanding of why or how things happen. That two events A and B follow after one another makes us believe that they have caused one another. The more times and the closer in time $\mathrm{A}$ follows on $\mathrm{B}$, the more certain we are that there exists a causal connection. In empirical thinking there is no way, according to Dewey, of separating true and false conclusions, which leads to a number of false beliefs. Dewey's term "empirical" may, however, lead our thoughts in the wrong direction, since it gives the impression that the experience is empirically tested on some scientific basis. To avoid such misunderstandings the term experiential will be used in the following both to cover knowledge products that are the result of incomplete empirical testing and such where judgments are made too quickly.

Dewey attaches great value to reflexive thinking. Ideally, the individual should, in his view, carry out investigations in order to find facts speaking for or against the supposed solutions as well as using sensible reasoning to develop the implications of solutions, grouping phenomena, etcetera. The procedure can be considered logical, as work is conducted systematically with the help of methodical arrangements in order to ascertain that the reflection provides the best possible result. Dewey's reasoning may lead the thought to natural sciences and to situations where you settle for one solution. Reflective learning processes are also supposed to include other ways of relating in a reflective, better thought-out or more systematic way.

\subsection{Automatized learning and intuitive knowledge}

The line of thought may be developed further by adding a discussion of whether learning may also take place in an unconscious and automatized manner. Returning to Table 1, level one represents an implicit level where knowledge arises unconsciously and learning is automatized, in other words, taking place without conscious intention and without our being 
aware of it. This means that one cannot choose to learn implicitly, since it just happens in an automatized way. It is true that the learner has a free choice, but only the explicit method can be chosen.

Kihlstrom, the cognitive researcher, (1999) claims that there are automatic "thought processes" going on inside the brain, independently of conscious intention and without our being aware of it. The ability to perform automatic processes is, according to him, partly inborn and partly automatized by originally conscious processes through training and practice. Damasio tells us about the very comprehensive and important unconscious processes affecting learning (Illeris, 2007). Hartman (1998) maintains that human beings are constructed for drawing general conclusions from experienced regularities and that they also automatically expect these regularities to remain. Dawkins (1998) claims that humans behave like intuitive statisticians, that is, they look for non-random statistical patterns. Lundh, Montgomery \& Waern (1992) discuss the concept of assimilation, claiming that man is generally restrictive, as there is always a selection of things that, so to speak, support what we already know. Eskola (1971) demonstrates that behavior dispositions and inner states such as needs, values, attitudes and moods affect human observations on the basis of some implicit personality theory.

It might be assumed that relations to the other, that is to say, the circumstance that we share a community with other people, help us to correct things that on closer view turn out to be unreasonable. In social psychology, on the contrary, it is asserted that people in a group tend to standardize their views (Nilsson, 1996). Horrocks (1966) maintains that humans are chained to their context and thus act as a group member. They are thus at least as much influenced by so-called group consensus as by their own perception.

At level one (Table 1) the knowledge process is assumed to take place continuously. The knowledge product emanating from unconscious knowledge processes is called intuitive knowledge or intuitive theories. The distinction makes it, at least theoretically, possible to contrast it to everyday knowledge. At all levels the knowledge process is manifested as products in the individual's own speech or thoughts, as well as in dialogues with others.

An essential aspect of knowledge formation and learning has, accordingly, been demonstrated. Thus it appears as if humans possess an automatized ability that enables them, for example like intuitive statisticians, on the basis of incomplete grounds to generalize knowledge which affects future perceptions. Various effects observed within social psychology also influence how we look upon the world.

It is essential to underline that an automatized knowledge process seems most rational, as it enables us to relate to a huge amount of information and still draw somewhat reasonable conclusions. What we "know" becomes a help to orienting ourselves in a world with a surplus of information. At the same time this knowledge prevents us from seeing the world "as it is".

It is of great importance in specific situations related to education or on more formal occasions to be able to distinguish between intuitive, everyday and scientifically based 
knowledge products. They form part of a long life history, whose first part is largely automatized. Separating knowledge products is, however, far from unproblematic, since they often have the same appearance regardless of their history of origin. One complication is that different kinds of knowledge processes are similar to one another, which paves the way for mixing them up. Thus everyday knowledge, like intuitive knowledge, is based on the human ability to generalize on incomplete grounds like an intuitive statistician. Likewise, everyday knowledge and scientific knowledge are explicit, but a result of experiential as well as of reflective learning. Everyday knowledge, however, takes up an intermediate position, as it has borrowed features of the other two forms of knowledge. Besides, knowledge products are momentary in being subjected to constant change, not least when articulated. In practice, knowledge process and knowledge product interchange all the time.

A further complicating factor is that the knowledge product representing scientific knowledge cannot be experienced in a "pure" state but is always mixed up with intuitive and everyday folk theories, since an automatized and experiential knowledge process goes on parallel or alternately even when we are reasoning or thinking reflectively. Furthermore, scientific knowledge is often, according to Wolpert (1992), in opposition to our intuitive theories and our everyday knowledge.

Ryle (1949/2002) has made a distinction between knowing-that and knowing-how. However, knowing-that refers to a context-free logical knowledge that individuals acquire via literature, lectures etcetera, while knowledge products in our sense are also seen as intuitive and everyday occurrences. Knowing-how is thus, according to Ryle, understanding that is linked to context and varies with attention, perception and judgment. Knowledge processes could have these characteristics, but are also a product of a reflected knowledge product.

\section{Implications for higher education}

Going back to the course as an example of how scientific reasoning may be "taught", this course can now be regarded as an attempt to handle some of the obstacles connected with implementing a reflective attitude to one's experiences.

The meaning of knowledge based on scientific reasoning is bound to different ontological and epistemological assumptions, whether positivist, hermeneutic or of some other nature. In accordance with Table 1 knowledge products are theoretical, since man is a theorizer. Intuitive theories are less often formulated in words and scientific theories more so, since they are products of conscious learning processes.

If one assumes that humans are condemned to be interpreters of reality, as held by the hermeneutics, then every statement is not a retelling of what really has happened, but of what has happened in the light of the present understanding of oneself and reality. Every new experience changes the conditions for the next. You cannot reach the world as it is because you are stuck in your already taken-for-granted world; you give some meaning to things and occurrences at the same moment as you apprehend them. Only if something astonishing happens do you start figuring out what it is, what is happening, and so on. 
Thus it can be argued that the students in the postgraduate course in the process of knowledge formation make theories out of reality as former pupils and about events changing their perspective. It can also be said that the knowledge process in itself transforms how the students apprehend these examples, for example when they discuss them or write them down.

For the sake of reflection on practical knowledge, the hermeneutic "trap" leads to the conclusion that every effort to grasp previous knowledge processes and products is fruitless. You can only reflect from your present standing point by a reconstruction of the past. The past as it was is forever tacit. Further, as a large number of the processes are automatized, you only remember fragments of former knowledge formation.

Practical knowledge seems, however, not tacit in the sense of being impossible to tell about, even though it is more intuitive. You might lack the adequate language, in the form of concepts and theories, but it is still possible to formulate what you know. The main difference, marking out practical knowledge from knowledge based on scientific reasoning, is that you more often gain practical knowledge without using words. To handle a hammer can be learned tacitly, but understanding "power”, “democracy” and "goodness” leads you into the universe of words, your own words as well as those of others. A problem in education settings is that some words do not have a uniform meaning. Since they are products of different knowledge processes, different meanings of the same word, for example "discuss" or "problematize", occur simultaneously without us noticing it. "Discuss" might be comprehended as talking over, debating, arguing, or analyzing. When the teacher instructs the students to discuss or problematize a certain issue, the process of reflection is disturbed by the connotations the students make from reminiscences from the past (Sellbjer, 2009).

Reflection on practical knowledge is to a large extent an effort at creating knowledge products in words, or, trying to formulate tacit aspects. Since knowledge processes are mainly automatized and experiential, it seems reasonable, as in the postgraduate course, to begin by producing a text in everyday terms and gradually introduce more reflection. To give words to something you just "do" is complicated enough to begin with. It also seems reasonable that you remember more learning processes that involve (strong) feelings. This highlights the phenomenon that one step of reflection is sorting out emotions from more "pure" thinking (see Donaldsson, 1992).

As a second step you distance yourself from the text written, thus becoming more reflective, by writing a new version. Since this involves harder work, you certainly need tools for reflection. A third step could be to challenge what has so far been taken for truth with the help of scientific theory. Various concepts and theories give alternative meanings and widen the scope of understanding.

Uljens' Culture and Freedom concepts can be used to illuminate the discussion made so far. Uljens (2004a) claims that man is born three times. The first birth, in his view, is into the world, i.e., the physical birth. The second birth is the birth into Culture, where the individual adopts an identity in a fairly unreflective way. It is both a matter of the individual gradually developing an empirical personal identity, and of this identity creation taking place in relation to the surrounding community, or, in relation to a linguistic and cultural intersubjectivity. 
This interhuman room that is constituted through language and action is termed by Uljens (2004b) the life-world, or practice. The consequence of the second birth is that of becoming a human being together with other human beings. It is, for instance, a question of determining the world linguistically by learning to name things, beings, places and cultural phenomena, a number of songs, hymns and maybe poems, sayings, jokes, etcetera.

Probably the knowledge products acquired in Culture make us somewhat resistant to change and new knowledge since we have established a platform that works quite well. Why then bother?

The third birth is the birth into Freedom and into a state of authority and of cultural autonomy, which enables passing beyond the prevailing situation. Being in Freedom means to have the ability to question why one adheres to certain values and beliefs and to view oneself as a carrier of insights and skills which can hardly be regarded as self-evident. It also means being able to conduct a metadialogical discourse vis-à-vis culture as well as questioning the same. One is, so to speak, "in dialogue with dialogue” (Uljens, 2004a). Here one may suppose some form of inner drift or motivation for change. However, this reasoning is not in focus in this text. Still, Uljens' concepts of Culture and Freedom give a deeper understanding of the obstacles we as university teachers have to handle trying to develop more advanced reflection processes.

One aspect of practical knowledge is that the acquisition of such knowledge mainly happens in Culture. Moreover, the knowledge process is to a large extent tacit. This means, with reference to the theoretical assumptions outlined in the previous section, that it is unconscious and automatized. You cannot tell when you learned or how you learned. Other parts of practical knowledge are products of experiential learning and maybe of reflective learning; the two latter being learning processes where you had a conscious intention to learn. Such processes may be possible to remember, but probably only if they were special in some respect; the first time I rode a bicycle myself, the first time I met a class and so on. One could also suppose that knowledge products gradually become automatized and in that way tacit.

An important aspect of the postgraduate course was to further develop a language involving talking and thinking of previous experiences as well as professional knowledge. If the meanings of the words used are mixed, to develop and use an adequate language is a first step, and to apply it in an advanced and reflected manner a second. This is also the reason why a course aiming to get the students to see a connection between their practical knowledge and experience, on the one hand, and the philosophy of science and theory of science, on the other, needs to include several steps. The course may be a first important step to freedom, but the process must fed back into work.

The product of reflection on practical knowledge can, however, only be apprehended as momentary. There are at least two reasons. First, automatized learning always occurs parallel to reflection. Secondly, every reflection is a reconstruction of the past, and there is always a new past (compare the hermeneutic circle). Accordingly, every new text is yet another reconstruction of something which will never be seen again. 
What about the other? Could it not be that participating in a culture and a language community as well as associating with other people in an experiential dialogue entails that the individual takes some steps towards freedom. Our answer is "probably not". We are sooner formed by the way one thinks and speaks in culture, let's say in a certain working place. Why should others' intuitive and everyday knowledge challenge my intuitive and everyday knowledge? It is the birth into Freedom that makes it possible to scrutinize our own and other people's world of ideas, and here the dialogue with texts and other people is a powerful method for distancing oneself. Such a birth could at best take place within a postgraduate course for students.

\section{References}

Bereiter, C. (2002). Education and Mind in the Knowledge Age. Mahwah and London: Lawrence Erlbaum Associates.

Berg, L-E., Boglind, A., Leissner, T., Månsson, P., \& Värnlund, H. (1975). Medvetandets sociologi. En introduktion till symbolisk interaktionism. (Sociology of Mind. An Introduction to Symbolic Interactionism) Stockholm: Wahlström \& Widstrand.

Bruner, J. (1996). The Culture of Education. Cambridge and London: Harvard University Press

Dawkins, R. (1998). Unweaving the Rainbow. London: Penguin.

Dewey, J. (1910/1991). How we Think. New York: Prometheus Books. Retrieved from http://www.brocku.ca/MeadProject/Dewey/Dewey_1910a/Dewey_1910_m.html

Donaldson, M. (1992). Human Minds. An Exploration. London: Penguin.

Eskola, A. (1977). Socialpsykologi. (Social Psychology). Uppsala: Almqvist \& Wiksell.

Flavell, J. (1977). Cognitive Development. Englewood Cliffs: Prentice-Hall.

Hartman, J. (1998). Vetenskapligt tänkande. Från kunskapsteori till metodteori. (Scientific Thinking. From Knowledge Theory to Method Theory). Lund: Studentlitteratur.

Horrocks J. (1966). Editor's Foreword. In Sherif, M. In Common Predicament. Boston: Houghton Mifflin Company.

Illeris, K. (2007). Lärande. (Learning). Lund: Studentlitteratur.

Kihlstrom, J. F. (1999). Conscious versus unconscious cognition. In Sternberg, R. J. The Nature of Cognition. Cambridge och London: MIT Press.

Lundh, L-G., Montgomery, H., \& Waern, Y. (1992). Kognitiv psykologi. (Cognitive Psychology). Lund: Studentlitteratur.

Polanyi, M. (1967). The Tacit Dimension. London: Routledge

Ryle, G. (1949/2002). The Concept of Mind. Chicago: University of Chicago Press. Available: 
http://www.andrew.cmu.edu/user/kk3n/80-300/ryle1949.pdf

Schön, D. (1983). The Reflective Practitioner. New York: Basic Books. Available: http://books.google.se/books?hl=sv\&lr=\&id=ceJIWay4-jgC\&oi=fnd\&pg=PR7\&dq=sch \%C3\%B6n+the+reflective+practitioner\&ots=q65POZGVwk\&sig=OPkp-YNfe09h4UzL clUPdcqaTqA\&redir_esc=y\#

Schön, D. (1987). Educating the Reflective Practitioner. San Francisco: Jossey Bass

Sellbjer, S. (2010). Vetenskaplighet $i$ hela lärarutbildningen. (Science throughout Teacher Education) Skriftserie från Institutionen för pedagogik, psykologi och idrottsvetenskap 3. Växjö: Linnéuniversitetet.

Uljens, M (2004a). Arvet efter Kant (The Heritage of Kant). Vasa: Åbo Akademi.

Uljens, M. (2004b). Den pedagogiska paradoxens utmaningar (The Challenges of the Pedagogical Paradox). In Bengtsson, J. (Ed). Utmaningar i pedagogik. Lund: Studentlitteratur.

Vygotsky, L. (1934/1962). Thought and Language. Cambridge: Available: M.I.T. Press. http://books.google.se/books?hl=sv\&lr=\&id=bkz7stcdbKgC\&oi=fnd\&pg=PR11\&dq=vy gotsky+thought+and+language\&ots=6RkQ8sZ9Hv\&sig=GwUYZIRqzgX0tNhBRuTtM NLX0f8\&redir_esc=y\#

Wolpert, L. (2002). The Unnatural Nature of Science. Cambridge: Harvard University Press.

\section{Copyright Disclaimer}

Copyright reserved by the author(s).

This article is an open-access article distributed under the terms and conditions of the Creative Commons Attribution license (http://creativecommons.org/licenses/by/3.0/). 